\title{
The Factors Which Motivate Zimbabwean Teachers Amid the Economic Challenges the Country Is Confronted With
}

\author{
Victor Chaboneka Ngwenya \\ Department of Arts and Education Zimbabwe, Open University \\ Bulawayo Region, P O Box 3550, Bulawayo, Zimbabwe \\ Tel: 263-09-961741.E-mail: chaboneka2003@yahoo.co.uk
}

Received: November 16, 2014 Accepted: January 21, 2015 Published: January 27, 2015

doi:10.5296/jsss.v2i2.7016 URL: http://dx.doi.org/10.5296/jsss.v2i2.7016

\begin{abstract}
This research investigated the factors which motivate teachers in Zimbabwean public schools amid the economic challenges ravaging the country. A survey design was used to gather data on biography, motivators, demotivators, need fulfilment, need deprivation and possible motivators by means of a questionnaire consisting of seven open-ended questions. The qualitative data amassed was screened and categorised in themes. The responses of thirty-seven teachers indicated that participants were motivated by financial gains, job security and the availability of adequate resources, contrarily to the major findings of Maslow and Herzberg. The absence of these in their workplaces equally demotivates them. Interesting though was that, a few teachers claimed that autonomy, recognition and developmental supervisory strategies were appropriate ingredients needed for self-actualisation. They further suggested that all stakeholders should be mobilised in a collaborated manner to provide adequate resources and infrastructure in schools to minimise demotivating conditions. Constant salary reviews within affordability limits, government loans at nominal interest rates and renewal strategies were recommended. Incentives although popular were discouraged.
\end{abstract}

Keywords: Demotivators, Education managers, Incentives, Need theory, Remuneration, Satisfiers, Two-factor theory, Working conditions 


\section{Introduction}

For time immemorial, let alone in colonial Africa, the "carrot and stick" approach of motivation bordering on Taylor's scientific management thought has been the strategy for motivation which managers have universally employed at willy-nilly (Everard \& Morris, 1996). Consequently, employee motivation at work was conceived of in terms of rewards and punishments, relating mainly to extrinsic factors such as pay and tight supervisory control. In that scenario, it is incumbent upon the education manager to be cognisant of the socio-economic and cultural context of the African society when structuring organisations so that it is possible to predict and encourage productive human behaviour and performance without bordering on remuneration or the much publicised debate on incentives. The underlying assumption of this latter traditional view of motivation was that well paid workers performed well (Owens, 1995). Contrary to that view, behaviourist scholars argue that whatever motivation packages are put in place, they must energise subordinates to be productive at all levels regardless of the economic challenges they are confronted with.

\section{Background to the Study}

Zimbabwean civil servants in general and the teaching fraternity in particular year in and out clamour for better salaries yet the national cake from the employer's point of view is either limited or overstretched by developmental projects elsewhere which also take precedence. Cries for a living wage by teachers usually lead to wildcat strikes which government usually confronts with equal force in its attempt to bring sanity to its labour force. The war of words between the employer and the teachers' unions and the tug-of-war that usually follows zeroing on the escalating costs of commodities becomes a bone of contention. Teachers argue that the meagre incomes they would be receiving by then would have been eroded by the ever galloping hyper inflation rate.

Behaviourist scholars claim that during periods of economic meltdown and stagnation teachers have been found to stay in the teaching portfolio for wrong reasons at all (Stephens $\&$ Heil, 1998). Zimbabwe not being an exception to this assumption, 2009 was a historical period. The country faced cash flow and liquidity crunch problems. The economy was gradually shrinking and unemployment levels in the streets were high. Teachers who were employable elsewhere started migrating to neighbouring countries in search of greener pastures, hence, creating a brain drain to unprecedented levels. Those who stayed behind did so because prospects of getting employed elsewhere were dim. Later on the inclusive government was constituted which had a share of its problems as well, although scant attempts were made towards resuscitating the economy. The Ministry of Education through the parent body in its attempts to retain its highly qualified personnel it was losing to other countries due to hyper inflation which was rocking the country by then, introduced the incentive system (Sunday News Correspondent, 2014). In that light, $10 \%$ of the collected levy at a school was supposed to be paid to teachers as incentives as spelt out by the Secretary's Circular Minute No 5 of 2009. This move came as a relief not only to teachers whose salaries were nothing to write home about, but to the parents as well whose children's education was being compromised. To that end, some innovative School Development Associations gave teachers groceries on a monthly basis as part of their fringe benefits. On the other hand, management, not wanting to be outdone also, introduced extra lessons at an 
extra fee and acceptance fees at Grade one/Form one levels which further irked the Minister of Education (Shumba, 2014). These perks although controversial, averted a catastrophe which could have befallen the Zimbabwean education system by then. Some critics argue that had the situation gone unchecked, the post independent gains Zimbabwe had achieved in education would have been reversed, particularly its renowned high literacy rates in Africa.

However, with time and precisely in 2014, the government abolished all forms of incentives as pronounced by the Ministry of Primary and Secondary Education Circular Number 6 of 2014. The reason advanced was that, the system was being abused by teachers (Sunday News Correspondent, 2014). The Minister of Education observed that schools were no longer sticking to the terms of reference on which the system was introduced (Sunday News Correspondent, 2014). Several audit reports had revealed that many schools were paying their teachers more than the stipulated $10 \%$ (Shumba, 2014). This practice according to the Minister was unacceptable and left schools with little money for capital projects (Shumba, 2014), hence, its abolishment. Even the combative Teachers' union viewed it as unsustainable and divisive (Sunday News Correspondent, 2014) as it was never systematic. Instead, it relied on the financial clout of the parent body and teachers in the rural areas were left out of the gravy train due to limited resources.

The Chief Executive Officer of the Zimbabwe Teachers' Association (ZIMTA) further corroborated this opinion when he argued that, differentials in the incentive system were divisive and against the government's policy of creating an egalitarian society as pronounced by the ruling party's ideology of 1980 (Zvobgo, 2004). Consequently, qualified teachers shunned rural areas as the perks there were far less than those of their urban counterparts (Sunday News Correspondent, 2014), thus, defeating the equality/ equity considerations government embarked on at independence in its attempts to redress the imbalances of the past colonial regime (Zvobgo, 2004). It is against this voice of reason that government wanting to be accountable to its masses scrapped the incentive system amid dissenting voices from teachers and other stakeholders who felt that the abolishment was done without a due process. Teachers began 2014 a disgruntled lot, more so that, the increase in salaries they were promised during the 2013 electioneering period never met their expectations.

It is against that backdrop of events that, superordinates need to observe that human beings despite the odds they would be faced with in whatever given context are craving animals who are unique in their attempt to accomplish whatever task is at hand (Everard \& Morris, 1996). The cumbersome task which is bestowed upon management in this momentous scenario is to establish the motivational level or need deprivation subordinates would be operating at. This thrust is a critical factor in the education manager's attempt to direct human behaviour and performance towards organisational efficiency and effectiveness. In that way, schools may be propelled to greater heights with or without effort at all, as they embark on their journey to achieve academic excellence. The focus of this article, therefore, is to investigate the factors which motivate Zimbabwean teachers in their workplaces amid the hotly debated bread and butter issues which are always benchmarked on the prevailing Poverty Datum Line (PDL) against the backdrop of hyper inflation using Maslow's and Herzberg's theories.

\section{Theories of Motivation}

Theories of motivation which regulate the behaviours of education managers and 
subordinates are as abundant as the public institutions which they populate. The Hawthorne experiment which was conducted by Elton Mayo and his compatriot Fritz Roethlishberger during the Human Relations Movement era based on the welfare of workers was the genesis of motivational theories (Stoner, Freeman, \& Gilbert, 1995). The major findings were that human beings are wanting animals who are motivated by the achievement of their social needs. In this article, the need- based theory and two-factor theory (Decker, 2010) are going to be the centre of focus as espoused by Maslow and Herzberg respectively. Before embarking on the theory crusade, there is need to define the term motivation within this context.

\subsection{What is Motivation?}

The term motivation in this context is defined as getting results through people or getting the best out of the people (Everard \& Morris, 1996). The results do not fall from heaven like manna, education managers as 'social architects' need to structure the systems in such a way that actions are induced in subordinates either intrinsically or extrinsically. Human beings, being unique in their nature, bring with them different packages of skills, beliefs, taboos, interests and potentials to the organisation which need to be sychronised with organisational goals if performance is to be enhanced (Everard \& Morris, 1996). The mondus operandi for education managers in this scenario would be to empower subordinates with drives which would enable them to achieve organisational goals at different levels spontaneously. Professionals nowadays do not want to be pushed around like pieces of furniture neither do they want to be yorked to the chains of bureaucracy like a span of oxen (Everard \& Morris, 1996) amid an avalanche of human right charters which their mother countries are signatories to. Treating them in a dehumanising manner evokes the sympathies of union bodies which are eagerly waiting to blow the human right whistle anytime these are violated. In that respect, the underlying philosophy of this article is that education managers need to put structures and systems in place which will enable subordinates to deliver services required at any given time spontaneously. After that, they may detach themselves from the institution they superintend and stand at a distance so as to marvel the work of their hands in the same way God admired His creation.

\subsection{Maslow's Hierarchy of Needs Theory}

The need theory is based on the assumption that employee's degree of work is catapulted by certain drives which are inherent in them (Decker, 2010). These needs range from basic physiological needs for survival to higher psycho-emotional needs like belonging and self-actualisation. At the lowest level, the employee is motivated by basic things such as breathing, food, water, sex, sleep, homeostasis and excretion. Perhaps this answers the reason why workers, as soon as they receive their first salary will yearn for food, shelter and clothing so as to restore equilibrium at this level. When these have been fulfilled according to Maslow, then safety needs will arise. Under this category, workers are looking forward to job security in terms of tenure ship and working conditions, availability of resources to accomplish given tasks, morality in terms of work ethics, security of the family in terms of benefits, medical coverage, pension schemes and accumulation of property based on their earnings. At this level, depending upon their salaries, some of their dreams begin to be realised and the purpose of work is also appreciated to the envy of the unemployed. 
The alluded to view above corroborates ethnographic studies conducted in Kenya and Malawi by Kiggundu (1988). His studies revealed that most African workers originate from a poverty stricken background and are highly motivated by financial gains when they work so as to meet their immediate social needs which their white counterparts have long achieved. Related to this view are the obligations of the extended family which characterise the African society. He also found that African workers were highly motivated by job security because of the prevailing unemployment rates caused by unpredictable shrinking and melting down economies, let alone, the presence of unemployed graduates in the streets.

Since human beings are craving animals by nature, when the above referred to, two levels have been achieved, Maslow believes that workers begin to yearn for affection within the organisation and family as well (Deckers, 2010). They want to belong to workers and professional organisations and begin to bridge the vertical relationship between them and their superordinate. This latter scenario was equally observed by Jones' ethnographic study (Blunt, Jones \& Richards, 1992) which revealed that African workers in Malawi wanted to be as close as possible to management and disliked close supervision. At this stage education managers need to be wary of both informal and formal groupings which began to sprout either for the good of the institution or to its detriment. However, when employees feel good, they then pursue their egos (Everard \& Morris, 1996) in the following attributes: titles, self-esteem, confidence, status symbols, achievement, awards, influence, prestige, respect of others and respect by others (Deckers, 2010). Such workers are propelled to greater heights when they are delegated challenging tasks which are relevant and achievable. When they have accomplished whatever task is at hand, their efforts need to be recognised either verbally or materialistically (Owens, 1995). In the former, positive reinforcement such as praises may be applicable whereas in the latter scenario tangible things such as a certificate of appreciation would suffice. Funds permitting, a meal with the subordinate or a recognition bonus would be ideal, let alone, the use of promotion as an alternative motivator (Everard \& Morris, 1996). Interesting to note though in this context is that African workers' egos were found to be congruent with those of workers in the Western cultures (Blunt, Jones, \& Richards, 1992).

All things being equal, Maslow believes that when an employee has achieved the four levels of motivation, which is not always possible (Blunt, Jones, \& Richards, 1992), then the next drive is to attempt to become the best of what one is capable of becoming through a process of self-actualisation (Deckers, 2010). At this level the worker needs more of autonomy as opposed to directives and bureaucratic tapes as they engage in problem solving activities (Owens, 1996). Educational resources need to be availed to subordinates so that they could operate independently if creativity and spontaneity are to take their toll. Perhaps in the event of the system faltering, management may come in as the backup force while the organisation is in an auto-pilot mode. Similarly when subordinates want to advance themselves academically, then time should be created within the work timeframe without compromising the learning of the children and their working conditions.

However, since Maslow's Hierarchy of Needs theory lacks empirical evidence which supports the idea that human needs are met in that hierarchical fashion, this makes this psychological arsenal to be a bad predictor of what really motivates subordinates in any one given work situation (Owens, 1995), hence the need to blend it with other theories. On the other hand, to 
assume that a met need is no longer a motivator (Everard \& Morris, 1996) is equally a misnomer. For stance, if sex is a motivator at a physiological level, why then do humans continue to crave for more, instead of actually extinguishing this desire? This is what makes human beings complex animals who are motivated by different things which cannot be delineated in that neat fashion (Stoner, Freeman, \& Gilbert, 1995). Going by that view, some individuals may join organisations to meet-lower order needs as revealed by ethnographic studies conducted in Africa while others may yearn for the opposite ones. Without being prescriptive, education managers need to be crafty and tailor contingent motivational approaches which will suit individuals in their social and cultural context (Stone, Freeman \& Gilbert, 1995) as they are not 'all size fit it all'. Transplanting motivational theories as conducted in the Western society with its different political, socio-economic and cultural background (Blunt, Jones, \& Richards, 1992) is anathema in this time and age.

\subsection{Herzberg's Two-Factor Theory}

Contrary to Maslow's Needs theory, Herzberg's attempted to focus on the job content itself as a primary source of motivation although not supported by empirical studies (Deckers, 2010). He categorically rejected that money and other forms of compensation were the most effective forms of motivation to the employee. This is the basis on which African scholars criticise Herzberg's theory as the bulk of participants in his research were engineers whose social status was affluent. The exclusion of those from impoverished backgrounds who partake in routinised and boring tasks make his findings sceptical (Blunt, Jones, \& Richards, 1992). His theory is divided into two parts. The lower levels of motivators which are akin to Maslow are called dissatisfiers/demotivators and higher level ones are referred to as satisfiers/motivators (Deckers, 2010). Going by this assertion, according to Herzberg, it does not mean that the removal of dissatisfiers leads to the presence of satisfiers (Owens, 1995). For example, when workers are highly paid and the environment they are working in is favourable, this does not induce high levels of motivation (Blunt, Jones, \& Richards, 1992).

The dissatisfiers which he also dubbed as hygiene factors in this respect are: pay, job security, status, working conditions, fringe benefits, job policies and relations with co-workers (Deckers, 2010). These are regarded as prerequisites and serve as the foundation on which higher level needs can be built on (Everard \& Morris, 1996). Satisfiers considered to have a motivational effect are: The level of challenge in the task, the work itself, responsibility, recognition, advancement, intrinsic interest, autonomy and opportunity for creativity which would stimulate satisfaction within the employee, provided that minimum levels of hygiene factors were reached (Deckers, 2010). Similarly, Herzberg's critics believe that no matter how challenging or interesting the task at hand is, if the remuneration levels are low and working conditions unpalatable, dissatisfaction will crop up. Despite that view, its proponents believe that motivators should be in built in the job itself such that employees are intrinsically rewarded by achieving the task at hand (Owens, 1995).

What needs to be observed here is that, Herzberg's theory by then was propelled by the concept of job enrichment (Owens, 1995). The idea in this regard was to expand the job so as to give employees a greater role in planning, performing and evaluating their work, thus providing the chance to satisfy their motivators' needs (Deckers, 2010). For this level of performance to be realised, management must decontrol the organisation and feedback should be provided 
regularly and continuously (Owens, 1995). In addition to that, there is need also to expand the knowledge and skills of workers through self renewal strategies if organisations are to operate efficiently and effectively (Deckers, 2010). However, its major weakness lies in its fallacious statement which assumes that all workers have the same work orientation and satisfiers.

\section{Methodology}

In this article, the researcher is seeking to answer the question: 'What are the factors which motivate Zimbabwean teachers to attain school goals' in the Bulawayo Metropolitan Province despite the prevailing socio-economic conditions which are challenging? A qualitative paradigm was adopted in a form of a survey design. Issues raised in this regard were factors which motivate teachers to achieve goals against a background of economic hardships as viewed from Maslow's and Herzberg's lenses. A self-completion questionnaire was developed containing 7 items and was used to collect qualitative data from teachers on their biographic data, motivating factors, demotivating factors, need fulfilment, need deprivation and suggestions on motivational strategies. The questionnaire items were open-ended. This enabled access to indepth information and personal responses of a qualitative nature from respondents. The approach was adopted to tap unbiased data from them. The questionnaire prototypes were pilot tested and modified accordingly to minimise ambiguity and enhance clarity before use. The responses gathered were screened and categorised in various themes for analysis.

For this study, a research sample of 37 teachers was selected using a systematic probability sampling technique. The names of teachers per school were arranged alphabetically and beginning with the first name, thereafter every fifth one was chosen until the desired number of respondents was reached at. After that the researcher distributed the questionnaires in person to the respective schools within this jurisdiction and collected them at an agreed date. At each school visited, a letter issued by the Provincial Directorate permitting the researcher to conduct the research in the circuit under study was used for introductory purposes. As soon as the completed questionnaires were collected, the distribution register was destroyed to enhance anonymity and confidentiality of the data collected.

The analysis methodology followed acknowledged the fact that data collected were of a nominal nature since various variables in the data were classified into categories. Frequency tables and descriptive statistics were used to describe each questionnaire included within this aspect.

\section{Respondents}

Thirty-seven teachers' sampled questionnaires were used out of forty, thus resulting in a response rate of $(93 \%)$. The three discarded ones were returned uncompleted despite the repeated visits to such schools.

\section{Results}

Questions 1-2 of the questionnaire captured the respondents' biographic data of various characteristics as depicted in the frequency distribution presented in Table 1. 
Table 1. Biographic data of the respondents $(\mathrm{N}=37)$

\begin{tabular}{lcccc}
\hline & \multicolumn{5}{c}{ Teachers } \\
\hline 1. Gender & F & $\%$ & To & $\%$ \\
Male & 7 & 19 & 37 & 100 \\
Female & 30 & 81 & 37 & 100 \\
\hline 2. Teaching Experience & F & \% & To & 100 \\
Below 5 & 2 & 5 & 37 & 100 \\
6-10 years & 9 & 24 & 37 & 100 \\
$11-15$ years & 8 & 22 & 37 & 100 \\
$16-20$ years & 4 & 11 & 37 & 100 \\
21 years and above & 14 & 38 & 37 & 100 \\
\hline
\end{tabular}

Gender and teaching experiences of teachers.

Table 1 reveals that thirty (81\%) of the respondents were females and seven $(19 \%)$ were males. When this observation was interrogated further, heads revealed that the deployment of teachers in urban schools favoured women. In Zimbabwe, it is Ministry policy that married women join their spouses in the wake of the AIDS pandemic which has ravaged many families. When the same teachers' experiences were queried, it was encouraging to note that the majority of the respondents, twenty-six (71\%) had taught for more than eleven years with fourteen $(38 \%)$ of these having taught for more than twenty-one years. Their experience in the teaching fraternity made the researcher conclude that their responses to the phenomenon under investigation could not be ignored. These were, therefore, considered valid and reliable within the parameters of this study.

\subsection{Motivating Factors}

Theories of motivation conducted by Maslow and Herzberg in developed countries reveal that workers are motivated by high order needs (Deckers, 2010). Contrary to these findings, ethnographic studies reveal the opposite. The purpose of this study was to establish what exactly motivates Zimbabwean teachers to do whatever they do, despite the economic hardships which the country is experiencing through question 3 and the results were as manifested below in their rank order. 
Table 2. Factors which motivate teachers $(\mathrm{N}=37)$

\begin{tabular}{lllll}
\hline Motivators & F & \% & To & \% \\
\hline 1. Conducive working conditions & 33 & 89 & 37 & 100 \\
2. Adequate teaching and learning materials. & 20 & 54 & 37 & 100 \\
3. Autonomy and Recognition & 16 & 43 & 37 & 100 \\
4. Teamwork & 10 & 27 & 37 & 100 \\
5. Parental involvement & 8 & 22 & 37 & 100 \\
6. Disciplined learners & 6 & 16 & 37 & 100 \\
7. Quality education & 5 & 14 & 37 & 100 \\
\hline
\end{tabular}

The factors which motivate teachers.

Table 2 reveals that teachers in the schools investigated are motivated by conducive working conditions (89\%). Attributes raised under appropriate working conditions were: remuneration and incentives, effective supervisory systems, communication networks, interrelationships, school climate and reduced teacher/pupil ratio. The findings reveal that teachers in Zimbabwe are motivated by lower order needs/ hygiene factors as observed by Maslow's and Herzberg's respectively. This observation confirms a research conducted by Kiggundu (1988) which revealed that workers in African countries are motivated by financial gains and security of employment so as to meet extended family obligations, a contradiction of the need and two-factor theories alluded to in this study.

Second in rank on the motivating agenda was the availability of teaching and learning resources (54\%) such as textbooks, stationery and library facilities. Despite the hyper inflationary salaries teachers are currently receiving, the presence of some who are motivated by autonomy and recognition (43\%), is a flicker of hope as this finding is in congruent with motivating factors inbuilt in the job itself as revealed in stable economies by Herzberg's study (Owens, 1995). What it means is that some teachers found teaching intrinsically rewarding. This sentiment although rated lowerly, should not be ignored. Perhaps the presence of the highly dedicated, committed and experienced teachers could have influenced this observation. To enhance this phenomenon, management faced by such a scenario could democratise their leadership style, empower teachers, flatten the organisational hierarchy and let them operate as autonomously as possible (Stoner, Freeman, \& Gilbert, 1995), more so, that African workers were found to dislike structures with centralised power (Blunt, Jones, \& Richards, 1992). In the process, two-way communication networks should be established to allow information to filter both ways unhindered and bureaucratic reporting procedures associated with a rigid structure should be discarded (Owens, 1995). In that way, production levels may raise. Little wonder that, despite the odds they are confronted with a few respondents still believed that quality education (14\%) could be realised although ranked the seventh. All what is needed perhaps in this scenario are proactive education managers who would capitalise on this dream and allocate willing teachers challenging tasks for them to excel, in return earn the much needed autonomy and recognition they yearn for (Deckers, 2010). This would be fertile 
ground for a quality crusade.

Furthermore, some teachers still felt that the quality crusade may be realised through teamwork $(27 \%)$ as opposed to individual competition. Others believed that if parents could also be involved $(22 \%)$ in the provision of education in both curricular and non-curricular issues, their efforts would go a long way towards alleviating their plight as they sought to achieve academic excellence. Above all, teachers were convinced that if proper disciplinary procedures $(16 \%)$ would be put in place in the absence of corporal punishment a lot would be achieved. In that view, they preferred intrinsically motivated learners who would do their homework regularly without pressure, attributes which would no doubt reduce the stress they were experiencing as some learners were becoming unmanageable.

\subsection{Demotivators}

Having established the factors which galvanise teachers into action, there was need to establish the factors which demotivate them from the Western and African perspective through question 4 and the results are portrayed below in their rank order.

Table 3. Factors which demotivate teachers $(\mathrm{N}=37)$

\begin{tabular}{lllll}
\hline Demotivators & F & \% & To & \% \\
\hline 1.Poor working conditions & 37 & 100 & 37 & 100 \\
2. Lack of teaching and learning resources. & 20 & 54 & 37 & 100 \\
3.Lack of parental involvement & 13 & 35 & 37 & 100 \\
4.Poor interpersonal relationships & 10 & 27 & 37 & 100 \\
5.Policy issues which negate practice & 7 & 19 & 37 & 100 \\
6.Lack of drive & 2 & 5 & 37 & 100 \\
\hline
\end{tabular}

The factors which demotivate teachers.

Table 3 reveals that teachers are demotivated by poor working conditions (100\%) and lack of teaching and learning resources (54\%) respectively. In the former issues such as the poor remuneration regime which they claimed was below the Poverty Datum Line, the bunching of salaries regardless of one's seniority, the scrapping off of the famous and infamous incentive system which was introduced by government at the height of economic meltdown, improper supervisory system, the presence of too many unqualified teachers, perhaps due to the brain drain experienced, demotivated them. Similarly, being reduced to scribes in the advent of computers was equally frustrating. They suggested that schemes of work, plan books and records be computerized. On teaching and learning resources, although they applauded the efforts of the United Nations which has supplied them with textbooks in all the subject areas, thus reducing the pupil/textbook ratio to one is to one, they still complained that the materials were not varied as learners were exposed to one textbook only. The unavailability of rich library facilities and the practising of double-sessioning in most public schools aggravated their plight. 
In the same vein, some teachers complained that non-payment of tuition fees by some parents on time (35\%) affected the performance of learners who were frequently absent due to this predicament, particularly those schools located in poverty stricken areas. This development is disturbing as it is at cross purpose with the policy of education for all pronounced at post independence (Education Act, 1987). On interpersonal relationships (27\%), they believed that management was heavy-handed, divisive as decisions were based on favouritism and lacked unity of purpose, perhaps caused by their preferred closeness to management (Blunt, Jones \& Richards, 1992). They also criticised the recruitment and assessment policy (17\%) of learners and teachers respectively. They argued that some learners were too young to contain the pressures of the wide curriculum of the Primary syllabus while other managers never considered their inputs when evaluating their performance. At the end of it all, it is factors such as these highlighted above which if present in any institution, make teachers lack the self-drive $(5 \%)$ to self-actualise their potentials latent in them.

What can be deduced from the above findings is that the factors which demotivate teachers in Zimbabwean schools in general and Bulawayo Metropolitan Province in particular, are congruent with those established in developed countries as observed by Maslow and Herzberg (Everard \& Morris, 1996). The major difference observed in the schools which were investigated is that, the very factors which are considered to be demotivators are motivators from the African perspective. Whilst one may surmise that teachers in Zimbabwean schools are operating at a lower level of need deficiency, their socio-economic background must be factored in, if their state of being is to be appreciated. It is therefore, paramount for education managers in this context to establish the deficient levels of subordinates before prescribing the appropriate motivational strategy.

\subsection{Need Fulfilment}

When teachers were interrogated on whether their needs were being met at the level of operation, the bulk of them indicated that as long as the working conditions, teaching and learning resources, interpersonal relationships, supervisory practices, parental involvement programmes did not, improve, they did not see how their needs would be fulfilled. They argued that the absence of these plus well co-ordinated remedial programmes for learners militated against their desire to self-actualise. Encouraging though was the fact that, they all believed that the presence of staff development programmes were a necessary evil if they were to be kept abreast of the current developments in knowledge and educational pedagogies (Deckers, 2010), which is one of the tenets of the total quality management paradigm (Sallis, 1996), if organisational efficiency and effectiveness is to be realised.

\subsection{Need Deprivation}

Having established factors which hinder self-actualisation, it was necessary at this level of the investigation to establish whether there were areas in the teaching field were they thought their needs were being deliberately denied or unmet. Question 6 was meant to unearth such sentiments. The bulk of them indicated that they were disappointed by the fact that government despite promising them hefty salaries during the electioneering period, their salaries were still below the Poverty Datum Line and incentives which had become means for their survival had also been scrapped (cf par 2). The abolishment of the latter has placed them back in the pre-dollarisation era. Related to these demotivating factors is the unavailability of 
varied teaching and learning resources, the large teacher/pupil ratio, the double sessioning, the punishment policy system in existence in schools presently in the absence of corporal punishment, the wide curriculum which they believe is unmanageable and negative interpersonal relationships in existence in schools make them dysfunctional. Such issues could have been clarified further if an interview had been employed.

What the above findings reveal is that teachers are really motivated by bread and butter issues in this context which confines them to Maslow's lower order need levels and Herzberg's maintenance/hygiene factors, perhaps due to their social and cultural background alluded to earlier on. In this view, the wholesome application of Maslow's need theory in the African workplace as a psychological arsenal for predicting human behaviour should be taken with a pinch of salt. The task of management in this context is to scan the social and cultural environment they find themselves in before imposing Western work organisational motivation structures on schools. Mismatches in developed countries were found to breed organisational malaise such as high turnover and absenteeism (Blunt, Jones, \& Richards, 1992), a situation which is detrimental to organisational development.

\subsection{Possible Suggestions}

When they were asked through question 7 , to make suggestions as how the motivational levels of teachers could be improved within the torrid conditions they were operating in, the following were made in rank order.

Table 4. Possible solutions $(\mathrm{N}=37)$

\begin{tabular}{lcccc}
\hline Attributes & F & \% & To & $\%$ \\
\hline 1. Working conditions & 37 & 100 & 37 & 100 \\
2. Infrastructural development & 9 & 24 & 37 & 100 \\
3. Intructional materials & 6 & 16 & 37 & 100 \\
4. Payment system for fees & 2 & 5 & 37 & 100 \\
5. Sports academy & 1 & 3 & 37 & 100 \\
6. Staff develop administrators & 1 & 3 & 37 & 100 \\
7. E-Learning & 1 & 3 & 37 & 100 \\
\hline
\end{tabular}

The possible solutions to factors which demotivate teachers.

Table 4 manifests that all the teachers investigated suggested that top on their motivational agenda were the working conditions (100\%) which they thought should be addressed promptly. The issues raised under this theme were varied. Some claimed that the current teacher/pupil ratio which stands at 50 must be reduced to something between 35 and 40, although on the part of government this has serious financial implications. Some even buttressed this response by claiming that, such a reduction would on the long run create employment. Others went further to suggest that it was high time teachers' salaries were debunched if the tested and tried senior teachers were to be retained and motivated by the 
system. Coupled to this assertion was that the hardworking teacher must be equally be rewarded by whatever means available. They reiterated that repetitive routines such as scheming and planning should be done away with, more so, with the advent of computers. In addition to that, as players in the educative enterprise, they wanted: to be consulted first on whatever changes government wanted to install in schools, specialisation be introduced in Primary Schools to minimise the burden of planning for over ten subjects and government avail to them interest free loans so that they could buy properties such as cars and houses. The latter view according to those who elaborated on the issue, commented that it was degrading and humiliating for them to be tenants in a building owned by parents whose children they teach, particularly when one is in rent arrears.

Besides that, some respondents also suggested that schools engage in various fund raising activities or seek donations from different stakeholders for infrastructural development and refurbishing their battered structures (24\%). This in their view would reduce the double-sessioning which they so much abhor. Interesting though, is the suggestion by some teachers that a textbook levy be introduced for purchasing instructional materials (16\%). The idea although brilliant, is a paradox of those who purported that schools introduce affordable fee payment systems (5\%) to avoid learners absenting themselves due to non-payment of these. The notion if adopted would be an extra-burden to the already financially over-stretched parents. Moreover, such a move would bring about inequalities in the provision of education, as affluent communities would be better off resourced than those which are impoverished. In the long run an egalitarian society Zimbabwe sought to construct at independence would be defeated in the process (Zvobgo, 2004). Finally, the following sentiments: existence of a sports academy meant to cater for non-academic learners, democratisation of organisational structures, adoption of developmental supervisory strategies and introduction of e-learning packages although mooted by individual teachers, the researcher feels that they need to be taken seriously if a conducive organisational climate which caters for various needs of learners and teachers included is to be developed.

\section{Conclusion}

The general view derived from this empirical research is that Zimbabwean teachers teaching in Bulawayo Metropolitan Province due to their socio-economic and cultural background are motivated by conducive working conditions which entail pay, fringe benefits, incentives, job security and developmental supervisory strategies. This is evidenced by their clamouring for the return of incentives which government scrapped off and demand for a living wage which is above the PDL. They buttressed this opinion by suggesting that government should give them interest free loans to enable them acquire basic needs of a physiological nature which according to Maslow's hierarchy are low level ones. When it comes to work itself, they yearn for adequate varied teaching and learning resources which management in league with parents should provide in abundance if they are to perform as desired. On the contrary, the absence of the above enumerated factors made them dysfunctional. They further intimated that all stakeholders should be roped in for infrastructural development with the ultimate aim of minimising or eliminating double-sessioning which they so much abhor. They also opinionated that disciplinary measures enforced in schools should be user-friendly so as to make teaching manageable. 


\section{Recommendations}

Going by the findings of this empirical research, there is need for government, funds permitting to constantly adjust the salary levels of the teachers to satisfactory levels based on the PDL if the current brain drain which has hit the education sector hard is to be curbed. Similarly, current salary levels should cater for seniority and meritocracy. Alternatively, government loans at manageable and affordable interest rates could be availed for teachers to enable them to acquire properties of a basic nature to enhance their job security and status. Indirectly, such loans would bond teachers to the noble profession. Incentives of whatever form should be discouraged at all costs as these were found to be divisive and discriminatory. They benefitted teachers in economically powerful catchment areas as compared to those in impoverished ones, let alone, rural teachers.

Schools are encouraged to engage in aggressive fund raising activities. Seed money could be sourced from School Development Associations as their resource base is wider. Where financial targets are not met, donations can be sought from well-wishers. Such funds could be used for infrastructural development and in the sourcing of varied learning and teaching materials which are so much scarce in schools. In that way the quality of service delivery would improve.

Above all, self-renewal strategies should be put in place in a collaborative manner so as to update not only education managers but teachers as well on developmental supervisory practices, appropriate leadership styles, organisational structures, motivational strategies and pedagogical skills needed for effective and efficient realisation of institutional goals. Transplanting those developed in the West without adjustments would be counterproductive as political, socio-economic and cultural set ups are incongruent.

However the results of this investigation need to be interpreted with caution as the empirical research was confined to sampled Zimbabwean public schools in Bulawayo Metropolitan Province and the qualitative research design was employed at the time when teachers were aggrieved by the scrapping off of incentives amid the economic challenges they were facing. It is therefore, recommended that a replica be carried out either using a mixed method approach or at a macro level so as to either confirm or reject some of these findings.

\section{References}

Blunt, P., Jones, M. L., \& Richards, D. (1992). Managing organisations in Africa. Berlin: de Gruyler. http://dx.doi.org/10.1515/9783110850031

Deckers, L. (2010). Motivation, biological, psychological and environmental (3rd ed.). Boston: Pearson.

Everard, K. B., \& Morris, G. (1996). Effective school management (3rd ed.). London: PCP Ltd.

Government of Zimbabwe. (1987). The Education Act; Chapter 25: 04. Harare: Government Printers.

Kiggundu, M. N. (1988). "Africa". In R. Nath (Ed). Comparative management: A regional review (pp. 169-243). Ballinger, Cambridge, Mass.

Owens, R. G. (1995). Organizational behavior in education. New York: Allyn and Bacon. 


\section{Macrothink}

Journal of Social Science Studies

ISSN 2329-9150 2015, Vol. 2, No. 2

The Secretary's Minute Number 5 of 2009. Ministry of Education, Sports and Culture: Zimbabwe.

The Secretary's Minute Number 6 of 2014. Ministry of Primary and Secondary Education: Zimbabwe.

The Sunday News Correspondent. (2014). Scrapping of teachers' incentives justified: official. The Sunday News, Weekly, July, 16, 2014, p. 2.

Sallis, E. (1996). Total quality management in education (2nd ed.) London: Kogan Pages.

Shumba, P. (2014). Dokora clips school heads' wings. The Sunday News, Weekly, July, 16, 2014, p. 2.

Stephens, D. C., \& Heil, G. (1998). Maslow on management. New York: John Wiley \& Sons. Inc.

Stoner, A. F., Freeman, R. E., \& Gilbert, D. R. Jr. (1995). Management (6th ed.) Englewood Cliffs: Prentice-Hall. Inc.

Zvobgo, R. J. (2004). The organisation and administration of Primary and Secondary School Education. Harare: ZOU.

\section{Copyright Disclaimer}

Copyright reserved by the author(s).

This article is an open-access article distributed under the terms and conditions of the Creative Commons Attribution license (http://creativecommons.org/licenses/by/3.0/). 